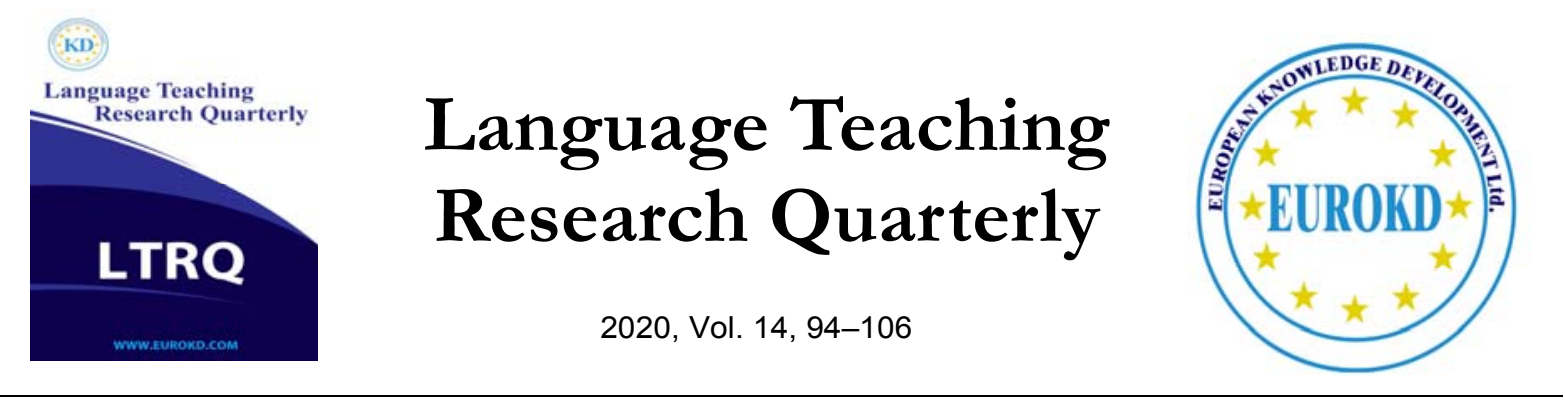

\title{
Improving Technical Translation Ability of the Iranian Students of Translation through Multimedia: An Empirical Study
}

\author{
Dina Zakeri ${ }^{1}$, Hamid- reza Kasikhan ${ }^{2}$ * \\ IAU/Shahre -e- qods branch, Tehran, Iran \\ IAU/Share-e-rey branch, Tehran, Iran
}

\begin{abstract}
Received 25 July 2019 Accepted 07 November 2019

Multimedia-assisted teaching results in eliminating traditional training barriers, facilitating cognition process and upgrading learning outcomes. This study attempted to examine the effects of implementing multimedia on teaching technical translation model and on the technical text translation ability of Iranian translation studies students. To fulfill the purpose of the study, a total of forty-six learners were selected out of fifty-seven participants in a higher education center in Tehran based on their scores in Preliminary English Test (PET) and were divided randomly in the experimental and control groups. Prior to the treatment, a technical text translation questionnaire was devised and then validated by three assistant professors of engineering fields and three assistant professors of Teaching English as a Foreign Language (TEFL) at the university. This questionnaire was administered as a pretest to both groups. Control and experimental groups were trained for five successive weeks using identical course books but with a different lesson plan that allowed employing multimedia for experimental group only. The devised and approved questionnaire was administered as posttest to both groups at the end of the instruction. A multivariate ANOVA was run to compare the two groups' means on the PET, pretest and posttest. The results showed the rejection of all null hypotheses of the study and revealed that multimedia significantly improved technical text translation ability of the learners.
\end{abstract}

Keywords: Multimedia, Multimedia-Mediated Teaching, Technical Translation Model, Technical Text, Translation Ability 


\section{Introduction}

The critical necessity for the translation of technical texts which include a wide range of subjects from law and medicine, economics and politics to information technology and media can no longer be disregarded. Unlike scientific translation which deals ideas and professions, technical translation concerns object and trades, and transfers information about how things are produced and work. Since technical texts are based merely on facts, their translations must strive to convey one meaning only. One of the supportive tools to help achieve this goal is multimedia that can make visual links between the text and the translator's mind. In order to be a successful technical text translator, other than the skills required to tackle language complexities, one should also know the language to communicate with specialists. Researchers have long questioned the ways a technical translator can improve this skill. Multimedia is one of the tools that suggest a leap from traditional translator-training courses to a modern multimedia-mediated translation courses. Valentini (2006), for example, described a multimedia database in his paper, A Multimedia Database for the Training of Audiovisual Translators, by centralizing the advantages it offers for audiovisual translator training. Moreover, Cho, Courville and Bengio (2015) studied multimedia content by using attention-based encoder-decoder networks and reported an impressively good performance and the advantage of the attention mechanism.

Multimedia, in fact, allows the trainees to retrieve the fundamental knowledge to overcome "a particularly vexing problem of technical translation [which] is ... vocabulary control (Nirenburg, Somers, \& Wilks, 2003, p.230). Because, Landers, C. E. (2001) also contended that in technical translation style is not a consideration so long as the informational content makes its way unaltered from source language to target language. In technical translation and specialty languages teaching, terminology is an essential topic that should be studied (Byrne, 2006). This implies that the trainees need facts beyond the dictionary meaning of the technical words. Consequently, multimedia can simply provide them with detailed information by means of three dimensional graphics, as an instance. While Newmark (1988) claimed that terminology accounts for at most just $5-10 \%$ of the total content of technical texts, this study underscores the merits of using multimedia in translator-training classes in Iran so that they will be encouraged to proceed as multimedia-mediated translators. The students learn to generate identical lexical and structural equivalents proposing the most accurate meaning within the process of using multimedia. The study examines how multimedia impacts the trainees' technical text translation skills.

Hence, with regard to the necessity of multimedia in translator-training classes as well as the existing gap in hereto research, the present study was carried out to address the following research questions:

RQ1. Is there any statistically significant difference between the effects of using images, compared to using no images, on teaching technical translation?

$\mathrm{RQ}_{2}$. Does using images have any significant effect on improving technical translation ability of the Iranian students of translation?

$\mathrm{RQ}_{3}$. Does using no images have any significant effect on improving technical translation ability of the Iranian students of translation? 


\section{Review of the Related Literature}

Believing that there is a growing tendency for language transfer in audiovisual media, Kline (2011) examined whether translation training is keeping up with theory on the translation process and its product and contended that studying and teaching translation for 7 multimedia purposes is a very complex matter for several reasons: the nature of the translation process, the diversity of media and requirements of the public in today's societies, the manner of introducing this skill to students.Valentini (2006) reviewed current needs and challenges of audiovisual translator training and defined the hybrid nature of audiovisual translation. He also described corpus construction methods and details of the conceptual architecture. The researcher finally concluded that limits and benefits of using a multimedia database is a component of AVT training.Velasco, Sánchez and Rodríguez (2008) introduced audiovisual material in the scientific and technical classroom and concluded that the learners were provided with precious instruments to encounter new challenges of the translation market.Nirenburg, Somers, and Wilks (2003) concluded that a puzzling problem predominant in technical translation is having control over vocabulary and that a technical word in the source language should be replaced by an appropriate technical word in the target language. What makes using multimedia an indispensible part of translation is that the amount of information received by the text is normally not enough for translators (Cintas, 2008).

\section{Method}

\section{Participants}

A total of forty six $(n=46)$ students out of 57 students of translation participated in this study. Only those students whose scores were one standard deviation (SD) above and one SD below the mean (based on the participants' PET scores) were selected and randomly divided into two groups of control and experimental, allowing 26 in each group. The participants were both male and female students in an age range of 22 to 45 who joined translator training courses in a higher education center for language studies in Tehran, Iran. To control the differences arising from nationality and mother tongue, they were all the Persian native speakers. The participants in the two groups, experimental and control group, were taught by the same.

\section{Instruments}

Various instruments were implemented in this study to examine the effects of using multimedia in teaching technical translation model for Iranian students of translation: i) a Preliminary English Test known as PET, ii) a questionnaire used as both a pre-test and post-test developed by the researcher based on the test booklets published by API (American Petroleum Institute) and which were approved by three assistant professors and board members of IAU, and iii) 9 instructional materials, subject matters, software and facilities used for treatment and API pamphlets for Fire Protection in Refineries, API Recommended Practice 2001, eighth edition, May 2005. 


\section{Preliminary English Test (PET) as Proficiency Test}

To ensure that the students in both experimental and control groups are benefitted from a homogenous level of EFL skills, a PET proficiency test of Cambridge ESOL examination 2011 was applied to screen the students before starting the training course. There were two discrete reading and writing sections in the test. The reading section contained 35 test items involving five parts. Part one was in the form of multiple-choice questions. Part two included a short text containing numbered blanks. Part three and four consisted of a number of short texts and part five included a cloze test. There were 7 test items including two writing tasks in the writing section five questions of which were of fill-in-the-blanks type for part one and writing a card to a friend for the second part. Part three consisted of a writing task asking students to write a text up to100 words.

\section{Technical Text Translation Questionnaire as Pre-test and Post-test Instrument}

In order to evaluate the contributors"e technical text translation capabilities, a standardized test was needed to be administered as pre-test and post-test to recognize the effects of the treatment on improving the studentse translation skills. Since there has never been developed a standardized test for technical text translation model to the moment to be used as pre-test and post-test, the researcher, first, collected tests published by API, American Petroleum Institute, API Recommended Practice 2001, eighth edition, May 2005. Then, Farsi translations based on the entries in the following resources were contrasted and selected to be the test items: i) Oxford Advanced Learner's Dictionary of Current English, A. S. Hornby, seventh Edition, 2005, ii) API 10 Recommended Practice 2001, eighth edition, May 2005, and iii) English- Persian Collegiate Dictionary of Aryanpur, 2004. The questionnaire consisted of 30 tests each of which bearing 4 choices of a) completely correct answer, b) completely wrong answer, c) half correct answer and d) an answer with a trap. The questionnaire, then, approved and validated by three assistant professors and board members of Technical and engineering faculty of IAU as well as three assistant professors of TEFL.

\section{Pilot-testing of Critical Thinking Questionnaire}

As a means of pre-test and post-test survey, the devised technical text translation questionnaire was piloted to approve the reliability required for the target sample. The pilot set included 20 students with identical knowledge of the proficiency language level to the participants in this study. The SPSS 16.0 package program was used to estimate the reliability of the questionnaire which was .805

\section{Instructional Materials for Treatment}

Byrne's (2006) Technical Translation, Usability Strategies for Translating Technical Documentation of University of Sheffield, UK, was the material used as course book to teach technical text translation model for both groups in this study. Moreover, short technical texts of mechanical, petrochemical and electronics engineering were taught to be translated into Farsi for 
the practical part of the course and workshop. Although participants received an equal amount of training in both groups, distinguishable methods and techniques were employed to train them in experimental group. Each training session of the course consisted of two distinctive theoretical and practical sections. Applicants in the experimental group were taught the course objectives, requirements and plans for the translation of technical texts including reality and misconceptions, nature, aims and theories of technical translation, translator's role, usability, cognetics, iconic linkage, interfaces, surveys and evaluations.

Samples and worksheets of API Recommended Practice 2001, eighth edition, May 2005, were, then, given to the trainees. While identical lessons, curriculum and sources were applied for both groups, participants in the experimental group enjoyed being assisted by a variety of field-related multimedia to translate the same text. In other words, learners in the control group had to do the rehearsal translations without being benefitted from mainly 3-dimentional animations, cross-sectional pictures and documentary films especially provided by API for training purposes. Whenever needed, the trainer intervened and replayed the instructional film, added cross-sectional pictures and provided time and space to review three dimensional slides and all types of available computer software such as Photoshop and AutoCAD related to the field.The same subject matters, materials, course book, rehearsal exercises, translation tasks which were applied to assign and train the participants in the experimental group were also used to teach learners in the control group, but they were not allowed to use multimedia for translation.

\section{Data Collection Procedure}

\section{Stage 1. Pilot Testing}

In order to ensure the reliability of the devised questionnaire, twenty learners of translation were selected to pilot the test before administering it as pre-test and post-test to the learners, although the test has already been approved by three assistant professors and board members of IAU and the estimation of its reliability proved to be high . The pilot group, similar to the target sample, took the test including 30 items and the results of the analysis designated that the questionnaire was reliable to be applied in this study.

\section{Stage 2. Homogenizing the Participants}

A population of totally 57 learners of translation was selected in order for the participants to be homogenized. They were all learners of mainly English to Persian translation who had passed EFL courses as a pre-requisite for the course. Thus, a sample reading and writing test of Preliminary English Test (PET) Cambridge ESOL (2011) was taken. The analysis of test scores showed that only 46 learners were qualified to participate in this study. Based on the learners ${ }^{\text {ee }}$ performance on PET examination, the learners were, then, distributed in two groups of 23 learners namely experimental and control groups. This grouping was randomly organized except for the high and low scorers who were equally divided between the groups. 


\section{Stage 3. Pre-test Administration}

In order to assess the learners ${ }^{\text {ee }}$ technical text translation skills before realizing the treatment, the devised questionnaire was administered as pre-test in both experimental and control groups. This was particularly done to evaluate the learners"e capabilities to translate technical texts in terms of vocabulary and localization. To do the test, learners were allowed to have access to paperback dictionaries of all types but not to multimedia probably installed on their smartphones or the like electronic devices such as iPods, nor to the internet. This was, also, the procedure operationalized in the control group while doing their translation tasks in the workshops. In other words, the learners in the control group were deprived of applying multimedia, animations or cross-sectional pictures and 3Ds.

\section{Stage 4. The Treatment Process}

Once the students were divided in small heterogeneous groups in the experimental group, the treatment started based on the lesson plan devised by Byrne (2006) for a course length of five weeks, holding two sessions a week each of which lasted one and a half hour. The training course had two distinctive parts: a theoretical part for technical translation model and a practical part and workshop for learners to practice translating short texts in the fields of petrochemical, 13 mechanical and electronics engineering. For the practical part in the experimental group, the trainer implemented all types of available multimedia including documentary films, crosssectional pictures and three dimensional slides to assist the technical text translation process. Nonetheless, learners in the control group received no assistance from any type of multimedia while doing their rehearsal translation tasks each session.

\section{Stage 5. Post-Test Administration}

The devised questionnaire was taken as post-test at the end of the course for both experimental and control groups to see if teaching technical text translation model through multimedia has improved technical text translation ability of the learners.

\section{Data Analysis}

The analysis of the statistics for the present study included parametric statistical analyses of multivariate ANOVA to investigate the null-hypotheses formulated on the basis of research questions and descriptive statistics to test all three main assumptions before reporting the main results: normality of the data, homogeneity of variances of the groups and homogeneity of covariance matrices. The normality assumptions were tested by calculating the ratios of the skewness and kurtosis over their standard errors. The assumption of homogeneity of variances was probed using the Levine's test and the assumption of homogeneity of covariance matrices was tested through the Box's test to determine whether multimedia-assisted teaching had any statistically significant effect on technical translation ability of the students of translation. 


\section{Results}

\section{Descriptive Statistics of the Pretest and Posttest Scores of the Groups' Translation Ability}

The participants of both the experimental and control group were administered a technical translation questionnaire which served as the pretest and posttest. The changes made are described in this section. Table 1 presents the results of descriptive statistics along with the 14 KR-21 reliability indices for the two groups in terms of their means on the pretest and posttest of technical translation. The reliability indices for the two tests were .82 and .81 .

Table 1

Descriptive Statistics and KR-21 Reliability Indices of Pretest and Posttest

\begin{tabular}{lccccccc}
\hline & N & Minimum & Maximum & Mean & Std. Deviation & Variance & KR-21 \\
\hline Pretest & 46 & 4 & 28 & 13.70 & 6.014 & 36.172 & .82 \\
Posttest & 46 & 6 & 29 & 16.67 & 5.846 & 34.180 & .81 \\
\hline
\end{tabular}

\section{Criterion Referenced Validity Indices}

The Pearson correlations between the pretest and posttest of technical translation with the PET test were computed as the criterion referenced validity indices of the former two tests (Table 4.2). As shown in Table 2 the pretest $(r(44)=.729$, representing a large effect size, $p=.000)$ and posttest of technical translation $(\mathrm{r}(44)=.593$, representing a large effect size, $\mathrm{p}=.000)$ enjoyed significant criterion referenced validity indices.

Table 2

Pearson Correlations between PET, Pretest and Posttest of Technical Translation

\begin{tabular}{llc}
\hline & & PET \\
\hline \multirow{3}{*}{ Pretest } & Pearson Correlation & $.729^{* *}$ \\
& Sig. (2-tailed) & .000 \\
& $\mathrm{~N}$ & 46 \\
\hline \multirow{3}{*}{ Posttest } & Pearson Correlation & $.593^{* *}$ \\
& Sig. (2-tailed) & .000 \\
\hline
\end{tabular}

${ }^{* *}$. Correlation is significant at the 0.01 level (2-tailed).

\section{Main Results}

Table 3 displays the descriptive statistics for the experimental (images) and control (no images) groups ${ }^{\text {ee }}$ means on the PET, pretest and posttest of technical translation. The experimental $(\mathrm{M}=$ $86.91, \mathrm{SE}=.96)$ and control $(\mathrm{M}=85.78, \mathrm{SE}=.96)$ had fairly close means on the PET test. The

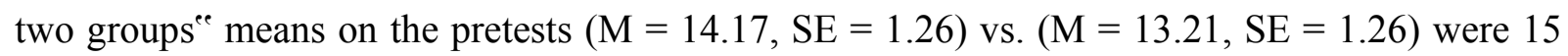
close; however, the experimental group had a higher mean on the posttest of technical translation $(\mathrm{M}=19, \mathrm{SE}=1.12)$ than the control group $(\mathrm{M}=14.34, \mathrm{SE}=1.12)$. 
Table 3

Descriptive Statistics; PET General Language Proficiency Test

\begin{tabular}{lllllll}
\hline \multicolumn{1}{c}{$\mathrm{N}$} & Minimum & Maximum & Mean & Std. Deviation & Variance \\
\hline PET & 57 & 57 & 98 & 82.58 & 9.175 & 84.177 \\
KR-21 & .84 & & & & & \\
\hline
\end{tabular}

Based on the results displayed in Table 4 it can be concluded thatthere was not any significant difference between the two groups ${ }^{\text {ee }}$ means on the PET test $(F(1,44)=.690, p=.411$, Partial $\eta 2$ $=.015$ representing a weak effect size). Thus it can be concluded that the two groups were homogenous in terms of their general language proficiency prior to the administration of the treatments. The experimental $(\mathrm{M}=86.91)$ and control $(\mathrm{M}=85.78)$ groups had close means on the PET. In addition,there was not any significant difference between the two groups' means on the pretest of technical translation $(\mathrm{F}(1,44)=.286, \mathrm{p}=.595$, Partial $\eta 2=.006$ representing a weak effect size). Thus, it can be concluded that the two groups were homogenous in terms of their ability in technical translation prior to the administration of the treatments. The experimental $(\mathrm{M}=14.17)$ and control $(\mathrm{M}=13.21)$ groups had close means on the pretest of technical translation. The experimental group $(M=19)$ significantly outperformed the control group $(\mathrm{M}=14.34)$ on the posttest of technical translation $(\mathrm{F}(1,44)=8.49, \mathrm{p}=.006$, Partial $\eta 2=$ .162 representing a large effect size) as was shown in Table 4.8 . Thus it can be concluded that the first null-hypothesis as ,there was not any statistically significant difference between the effects of using images, compared to using no images, on teaching technical translation "e was rejected.

Table 4

Descriptive Statistics; Testing Normality Assumption

\begin{tabular}{llccccccc}
\hline & & \multicolumn{3}{c}{ Skewness } & \multicolumn{3}{c}{ Kurtosis } \\
\cline { 3 - 9 } Group & & Statistic & Statistic & Std. Error & Ratio & Statistic & Std. Error & Ratio \\
\hline \multirow{4}{*}{ Experimental } & PET & 23 & .518 & .481 & 1.08 & .234 & .935 & 0.25 \\
& Pretest & 23 & .600 & .481 & 1.25 & -.821 & .935 & -0.88 \\
& Posttest & 23 & .166 & .481 & 0.35 & -.693 & .935 & -0.74 \\
\hline \multirow{3}{*}{ Control } & PET & 23 & -.005 & .481 & -0.01 & -.004 & .935 & 0.00 \\
& Pretest & 23 & -.232 & .481 & -0.48 & -.682 & .935 & -0.73 \\
& Posttest & 23 & .428 & .481 & 0.89 & -.146 & .935 & -0.16 \\
\hline
\end{tabular}

The last two research questions targeted the improvement in each group's means from pretest to posttest. Table 5 compares each group's means on pretest and posttest of technical translation. Based on these results it can be claimed that: The experimental group had a significantly higher mean on the posttest $(M=19)$ than pretest $(M=14.17)$ (Mean Difference $=4.82, p=.000)$. Thus it can be concluded that the second null-hypothesis as „using images did not have any significant 
effect on improving technical translation ability of the Iranian students of translation was rejected.

Table 5

Levene's Test of Equality of Error Variances

\begin{tabular}{lcccc}
\hline & F & df1 & df2 & Sig. \\
\hline PET & .001 & 1 & 44 & .981 \\
Pretest & 2.771 & 1 & 44 & .103 \\
Posttest & .020 & 1 & 44 & .887 \\
\hline
\end{tabular}

Figure 1 shows that there was not any significant difference between the control group's means on the posttest $(\mathrm{M}=14.34)$ and pretest $(\mathrm{M}=13.21)$ (Mean Difference $=1.13, \mathrm{p}=.068)$. Thus, it can be concluded that the third null-hypothesis as, using no images did not have any significant effect on improving technical translation ability of the Iranian students of translation was supported.

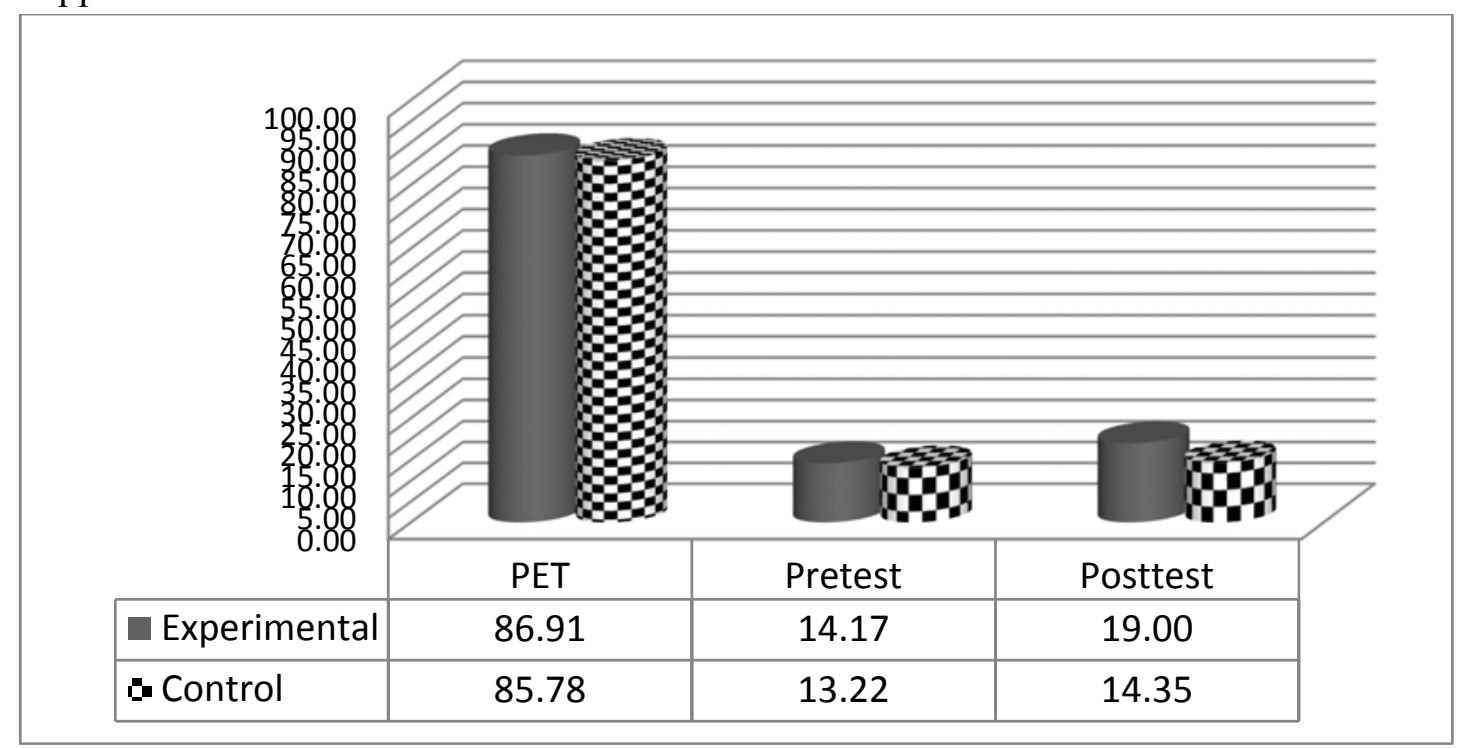

Figure 1. The Schematic Presentation of the Data Analysis

\section{Discussion}

Conventional methods of transferring a text from source language to target language which is done by the translator seem to be an only solution for all models including the translation of scientific, literary, religious, journalistic, diplomatic and technical texts. While most of these texts are informative and enjoy a free translation, technical translations relocate facts and figures about designing, manufacturing and applications and are expected to remain strictly close to the original text. Thus, a technical translator's familiarity with and his/her awareness of basic scientific principles and all the systems used in industrial contexts appears to be a pre-requisite, 
being technical information about "measurement units, acronyms, symbols and abbreviations, names of commercial products, item description systems, templates and patterns, [specifications] ... or the use of different materials" (Brown, 2006, p.594). However, instead of transferring the informative content of the original technical text, inexperienced translators urge to convey the expressive and aesthetic aspects of the message as is usually done in the translation of literary texts. Multimedia apparently can play an important role in training all these styles where a deeper understanding of the subject is a fundamental factor to maintain precision (Anderman \&Rogers, 2005;O'Hagan \& Ashworth, 2002; Kay \& Knaack, 2007; Vernadakis, et.al., 2008; Evans, et.al., 2008; Mayer, 2001; Hennessy, et.al., 2006; Wang \& Reeves, 2006).

The positive impact of implementing various modes of multimedia including text, audio, images, and video in language learning classes has already been verified by many researchers. for example, Yanguas (2009) studied the effect of multimedia glosses on L2 text comprehension and vocabulary learning and the results confirmed the effects; Plass et al. (2003) examined cognitive load in reading a foreign language text with multimedia aids and found that multimedia instruction can indeed lead to improved learning outcomes; Caimi's (2006) study suggested that employing multimedia facilitated learners' reading comprehension. However, due to traditional teaching methods employed in most, if not all, of the translator training centers in Iran, students are still less inclined to be technical translators. Moreover, an overview of the vocational background of professional translators indicates that technical texts have predominantly been rendered by specialists who enjoyed mastery over the field but that a limping proficiency of language has stained their translations. This clearly endorses the fact that the methodology for technical text translation courses is needed to be revised.

Multimedia-assisted teaching methods improved technical translation ability of the Iranian students of translation which is consistent with the findings of the researches accomplished by Bartlett and Strough (2003), Crosby and Stelovsky (1995), Harris and West (1993), Issa, Cox and Killingsworth (1999), Hennessy, Deaney, and Ruthven (2006), Khiyabani, Ghonsooly and Ghabanchi (2014), Pea (1991), and Vernadakis et.al. (2008). Thus, it could be deduced that the achieved results had already been approved by several other researches concerning the effects of applying multimedia as an assistance in teaching methods on the quality of learning in general and translation ability of learners in particular. Since other studies accomplished, to the moment, have also reviewed the effects of multimedia on improving the learnability of students, it could be construed that there is consistency of the results. Meanwhile, this research strove for finding whether multimedia-assisted teaching could improve technical translation ability of the learners in translator training courses.

This study targeted to review the effects of using multimedia in teaching technical translation model as compared to traditional methods on translation ability of the Iranian students of translation. While the majority of the students of translation could hardly develop to be technical translators through traditional methods of translator training courses where learners find the text difficult to understand, it seems that replacing them by multimedia-assisted training courses could be a solution. Students of translation rely merely on the text, accompanying illustrations 
and an engineering dictionary to translate technical texts which is not sufficient. A method to train students in engineering and technical fields, teaching through multimedia could also be successfully implemented to train students of technical translation as revealed by the results of the analysis in this study. To achieve this goal, a multivariate ANOVA accompanied by descriptive statistics for all test items and groups were implemented. Table 4.10 shows the multivariate ANOVA analysis employed to see if there is any statistically significant difference between the effects of using images, compared to using no images, on teaching technical translation. The translation ability of the learners in control group improved a little even without using images or any form of multimedia to teach; however, the improvement was not comparable with the one learners gained in the experimental group who enjoyed learning to translate technical texts through all sorts of multimedia including three-dimensional slides wherever needed. These results clearly imply that multimedia-mediated teaching in translator training courses has significant effect on improving the translation ability of the Iranian students of translation. Thus, relying on the research results of the present study and their consistency with the studies mentioned above, it would be safe to conclude that implementing several forms of multimedia to teach the translation of technical texts could hopefully be stressed in schools and may become an obligatory part of the syllabuses for translator training courses and could reliably be applied in universities, institutes, companies and public or private organizations. Moreover, information technology has changes the professional environment of scientific and technical translators, who must work with new formats and channels of information. To meet these new challenges, translation teachers must place special emphasis on the importance of the non-textual information evolving around multimedia texts and adopt a more dynamic approach. Consequently, we argue for the inclusion of multimedia material in the translation classroom as a valuable means for students to become familiar with emerging forms of translation which highlight the knowledge of the subject field and its conventions, combined with some knowledge of audiovisual formats.

\section{Conclusions and Implications}

As the literature review of the study suggested, multimedia has served in various fields of study, from sports like basketball to junior high-school subject matters like science, as a solution for educational problems (Vernadakis et.al., 2008; Hennessy, Deaney \& Ruthven, 2006). The results of the present research not only supported the findings of previous studies but also offered a solution for the technical translator's lack of awareness of basic scientific principles and all the systems used in industrial contexts. In other words, although deeper understanding of the subject matter is a fundamental factor to maintain accuracy in translation, the findings of the study 20 proved that if applied properly, multimedia in several forms such as instructional films, crosssectional pictures, three-dimensional slides, Photoshop and AutoCAD software can be implemented to provide abundant technical and scientific knowledge the translators might need. This might also imply that relying on the findings of the present study the quality of technical translations which has suffered from the engineerse limping proficiency of language, despite 
their mastery over the technical field, will probably be upgraded, if the methodology for technical text translation courses is revised.

The analysis of the data in this research revealed that implementing multimedia-mediated teaching systems in translator training courses considerably improved the technical text translation ability of the Iranian students of translation. Moreover, the study found that employing multimedia in translator training courses had significant effect on teaching technical translation model to the learners. As a result, teachers can be assisted by multimedia and threedimensional rolling images to increase learners' understanding of the text and improve their translation ability. Accordingly, the findings of the study could probably help syllabus designers in translator training courses to be more aware of the role multimedia can play to enhance teaching efficiency on the one hand and to improve translation ability of the learners on the other. These learners could be taught to view multimedia in technical translation fields as being the best resort to bridge the gap of insufficient technical knowledge of the translators. Thus, not only the learners and teachers could be benefited through using different kinds of multimedia in schools, but also curriculum developers and course designers in translation institutes may find advisable the results of the present study.

\section{References}

Anderman, G. \& Rogers, M. (Eds.) (2005). In and Out of English: For Better, For Worse? Toronto: Multilingual Matters Ltd.

Baker, M. (1991). In Other Words: A course book on translation. London: Routledge.

Bartlett, M. \& Strough, J. (2003). Multimedia versus traditional course instruction in introductory social psychology. Teaching of Psychology, 30, 335-338.

Brown, K. (2006). Encyclopedia of language and linguistics. London: Elsevier Social Sciences.

Byrne, J. (2006). Technical Translation: Usability Strategies for Translating Technical Documentation. Dordrecht: Springer.

Caimi, A. (2006). Audiovisual Translation and Language Learning: The Promotion of Intralingual subtitles. The Journal of Specialized Translation, 6.

Chantler, A. \& Dente, C. (Eds.) (2009). Translation Practices: Through Language to Culture. New York: Rodopi.

Cintas, J. D. (Ed.) (2008).The Didactics of Audiovisual Translation. Philadelphia: John Benjamins B.V.

Crosby, E. \& Stelovsky, J. (1995). From multimedia instruction to multimedia evaluation. Journal of Educational Multimedia and Hypermedia, 4(147-162).

Evans, K. L., Yaron, D. \& Leinhardt, G. (2008). Learning stoichiometry: a comparison of text and multimedia formats. Chemistry Education Research and Practice, 9, 208-218.

Gambier, Y. \& Gottlieb, H. (Eds.) (2001). (Multi) Media Translation, Concepts, practices, and research. Amsterdam: John Benjamins B.V.

Gilakjani, A. P. (2012). The Significant Role of Multimedia in Motivating EFL Learners ${ }^{e e}$ Interest in English Language Learning. I.J.Modern Education and Computer science: MECS, 4 (4-8), 57-66.

Harris, J. \& West, J. (1993). Using multimedia in hospitality training. The Cornell Hotel and Restaurant Administration Quarterly, 34(4), 75-82.

Hatim, B. \& Mason, I. (1997). The Translator as Communicator. New York: Routledge. 
Hennessy, S., Deaney, R. \& Ruthven, K. (2006). Situated Expertise in Integrating Use of Multimedia Simulation into Secondary Science Teaching. International Journal of Science Education, 28/7, 701-732.

Hofstetter, F.T. (2001). Multimedia literacy. New York: McGraw-Hill.

Issa, A., Cox, F. \& Killingsworth, F. (1999). Impact of multimedia-based instruction on learning and retention. Journal of Computing in Civil Engineering, 13(4), 281-290.

Kay, R. H. \& Knaack, L. (2007). Evaluating the learning in learning objects. Open Learning, 22/1, 5-28. 22

Khiyabani, H., Ghonsooly, B. \& Ghabanchi, Z. (2014). Using Multimedia in Teaching Vocabulary in High School Classes. Journal of Advances in English Language Teaching, 2 (1), 1-13.

Kline, B. M. (2011). Otherness - Challenge or Obstacle in Multimedia Translation. Komunikacijai Kultura online: Godina, II (2).

Landers, C. E. (2001). Literary Translation: A Practical Guide. Toronto: Multilingual Matters Ltd.

Mayer, R. E. (2001). Multimedia Learning. Cambridge: Cambridge University Press.

Nirenburg, S., Somers, H. \& Wilks. Y. (Eds.) (2003). Readings in Machine Translation. Massachusetts: The MIT Press.

Newmark, P. (1988). A Textbook of Translation. New York: Prentice Hall.

O'Hagan, M. (1996). The Coming Industry of Teletranslation: Overcoming Communication Barriers through Telecommunication. Clevedon: Multilingual Matters.

O’Hagan, M. \& Ashworth, D. (2002). Translation-mediated Communication in a Digital World. Toronto: MULTILINGUAL MATTERS LTD.

Pea, R. D. (1991). Learning through Multimedia. IEEE Computer Graphics \& Applications, 11(4), pp.58-66, hal00190567.

Plass, J. L., et.al. (2003). Cognitive Load in Reading a Foreign Language Text with Multimedia Aids and the Influence of Verbal and Spatial abilities. Computers in Human Behavior:PERGAMON, 19, 9221-243.

Tiako, P. F. (2009). Software Applications: Concepts, Methodologies, Tools, and Applications. New York: Information Science reference.

Valentini, C. (2006). A Multimedia Database for the Training of Audiovisual Translators, The Journal of Specialized Translation, 6.

Venuti, L. (1995). The Translator's Invisibility: A History of Translation. London: Routledge.

Vernadakis, N., et.al. (2008). Student attitude and learning outcomes of multimedia computer assisted versus traditional instruction in basketball. Educational Information Technology, 13, 167-183.

Wang, S-K. \& Reeves, T. C. (2006). The effects of a web-based learning environment on student motivation in a high school earth science course. Educational Technology Research and Development, 55, 169-192.

Yanguas, I. (2009). Multimedia Glosses and their Effect on L2 Comprehension and Vocabulary Learning. Language Learning \& Technology, 13(2), 48-67. 